\title{
Tuning the surface properties of polypyrrole films for modulating bacterial adhesion.
}

Mohsen Golabi, Anthony Turner and Edwin Jager

\section{Linköping University Post Print}

\section{Tweet}

N.B.: When citing this work, cite the original article.

Original Publication:

Mohsen Golabi, Anthony Turner and Edwin Jager, Tuning the surface properties of polypyrrole films for modulating bacterial adhesion., 2016, Macromolecular Chemistry and Physics, (217), 10, 1128-1135.

http://dx.doi.org/10.1002/macp.201500445

Copyright: John Wiley \&amp; Sons, Ltd

Publisher URL http://www.wiley.com

Postprint available at: Linköping University Electronic Press

http://urn.kb.se/resolve?urn=urn:nbn:se:liu:diva-128197 


\section{Full Paper}

\section{Tuning the surface properties of polypyrrole films for modulating bacterial adhesion}

Mohsen Golabi, Anthony P F Turner, Edwin W H Jager*

M. Golabi, Prof. A P F Turner, Dr. E W H Jager

Biosensors and Bioelectronics Centre, Dept. of Physics, Chemistry and Biology (IFM),

Linköping University, 58183 Linköping, Sweden.

E-mail: edwin.jager@liu.se

\section{Abstract}

Tuning the physical-chemical properties of Polypyrrole (PPy) opens up potentially exciting new applications, especially in the area of bacterial adhesion. Polypyrrole is electrochemically synthesised under various conditions and the physical properties of the films and their effects on bacterial adhesion characterised. Five types of dopants, chloride $(\mathrm{Cl})$, Perchlorate $\left(\mathrm{ClO}_{4}\right)$, pToluene-sulfonate (ToS), Dodecylbenzene sulfonate (DBS) and Poly sodium styrene sulfonate (PSS), are used to fabricate PPy films at two different constant potentials (0.500 and $0.850 \mathrm{~V}$ ) with and without $\mathrm{Fe}^{3+}$. Their thickness, roughness and wettability are measured. The adhesion tendency of Escherichia coli, as a model bacterium, to the four polymers is studied. E.coli shows greater adhesion tendency to the hydrophobic, rough surface of PPy-DBS and less adhesion tendency to the smooth and hydrophilic surface of PPy-PSS. The results facilitate the choice of appropriate electropolymerisation conditions to modulate bacterial adhesion.

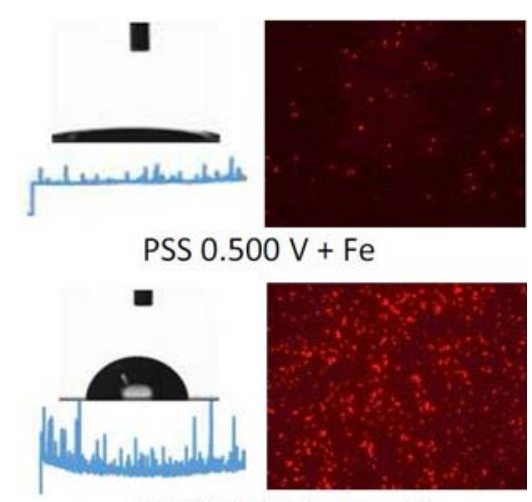

DBS $0.850 \mathrm{~V}+\mathrm{Fe}+\mathrm{Q}$ 


\section{Introduction}

The biocompatibility of polypyrrole (PPy) and its low cytotoxicity qualify it as a valuable conducting polymer for various purposes, including use in biosensors and biomedical applications. PPy has been widely used in systems for stimulation of stem cells, artificial muscle development, nerve regeneration, drug release control, bacterial cell entrapment and biosensing applications. ${ }^{[1-5]}$ In these cases, PPy played an active role as a smart conductive layer which was in contact with bacteria and cells. However, the physical properties of the polymer, including thickness, roughness and wettability play a key role in the final quality of the film and its suitability for its intended application, and these parameters need to be carefully determined and controlled. Chemical polymerisation has frequently been used to fabricate PPy, but electropolymerisation offers advantages including simplicity, speed of formation and controllability. It also facilitates integration with electrodes for transduction or actuation. Although PPy has been used widely in scientific research and is well characterised, there are a paucity of studies on tuning its surface physical properties during fabrication of polymer to deliver the optimum properties. There are some reports on the effects of different synthesis conditions including $\mathrm{pH}$, solvent, substrate, temperature and the type of dopant on final physical properties of PPy. ${ }^{[6-9]}$ However, there is a still needs for more insight into how to apply electropolymerisation conditions to control surface properties in order to tune the final properties of the PPy films produced.

Biofilm formation starts with initial bacterial adhesion. The adhesion tendency of a bacterial cell to a surface is determined by three key parameters: the properties of the surface material; the type of bacteria; and the environment conditions. ${ }^{[10]}$ Although the molecular and physical interactions of eukaryotic and bacteria cell with biomaterials have not been clearly understood in detail, ${ }^{[11,12]}$ chemical composition, charge, roughness and hydrophobicity of the surface of materials have been frequently reported to be important parameters. ${ }^{[10,13,14]}$ Therefore, it is clear that changing the physical-chemical properties of PPy could lead to static modulation of 
its adhesion properties for bacteria and human cells. Elucidating the effects of synthesis conditions on the material properties will help fabrication of PPy, and other conducting polymers, with favourable properties towards a specific application. In this paper we focus on bacterial adhesion.

We used five types of counter ions to electrochemically fabricate PPy under different polymerisation conditions in order to understand how to tune the physical properties of thickness, roughness and wettability, by altering the synthesis parameters. We documented the effect of these on bacterial adhesion, which may be desirable or undesirable, depending on the application. In order to tune the PPy film, we selected three important synthesis parameters: applied potential; consumed charge (which equals synthesis time); and the addition of $\mathrm{Fe}^{3+}$, which has been shown to have a large impact on the PPy surface properties. ${ }^{[15]}$ We investigated the two extreme potentials: V=0.500 V and V=0.850 V vs Ag/AgCl. Potentials lower than 0.500 $\mathrm{V}$ leads to poor film formation and potentials higher than $0.850 \mathrm{~V}$ leads to overoxidation and non-conductive films. ${ }^{[6,16-18]}$

\section{Experimental Section}

\subsection{Polymer synthesis}

Pyrrole monomer (Sigma-Aldrich), distilled after delivery and stored at $-20^{\circ} \mathrm{C}$, was used to electrochemically synthesis polypyrrole film on gold coated silicon chips using a threeelectrode electrochemical cell coupled to a Compactstat.e potentiostat (Ivium Technology, The Netherlands). The polymerisation solution contained $0.1 \mathrm{M}$ distilled pyrrole monomer in deionised water (Milli Q, 18.2 M $\Omega$ ) plus $0.1 \mathrm{M}$ of the selected counter ion, Sodium p-toluenesulfonate (ToS, Acros Organics, New Jersey, USA), Dodecylbenzene sodium sulfonate (DBS, TCI Europe), Poly sodium 4-styrene-sulfonate (PSS, Sigma-Aldrich), $\mathrm{NaHClO}_{4}$ or sodium chloride (Sigma-Aldrich). $1 \mathrm{mM} \mathrm{FeCl}_{3}$ (Sigma-Aldrich) was added before the polymerisation 
process in selected experiments to catalyse the chemical polymerisation. A constant potential (500 or $850 \mathrm{mV}$ ) was used to deposit PPy to assure that all samples are synthesised at the same oxidation potential, resulting in PPy surfaces with the same properties ${ }^{[19]}$. PPy was deposited on gold coated silicon chips using $1 \mathrm{~cm}^{2}$ (10 mm by $10 \mathrm{~mm}$, accessible surface) as the working electrode, a platinum mesh as the counter electrode and $\mathrm{Ag} / \mathrm{AgCl}$ as the reference electrode. The polymerisation was stopped after a predetermined amount of charge had been passed, 200 or 800 micro-Coulomb (mC). Table 1 summarises the synthesis conditions used for the different versions of PPy used in this study.

\subsection{Polymer surface characterisation}

The surface thickness and roughness profile of the polymer samples were determined by using a Dektak 6M Profilometer (Veeco Instruments Inc., NY). For determination of the wettability of the PPy samples, the static water contact angles of the films were measured using the sessile drop technique with fresh Milli Q water (18.2 M $\Omega$ ) with the aid of a CAM200 Optical Contact Angle Meter (KVS Instrument, Finland). Scanning Electron Microscopy (SEM) images were taken using a Leo 1550 Gemini SEM operating at $8.0 \mathrm{keV}$.

\subsection{Bacterial adhesion tests}

The bacterial strain, Escherichia coli, used in this study was obtained from Culture Collection University of Gothenburg. E.coli was cultured in Tryptic Soy Broth (TSB) overnight (18hrs) at $37^{\circ} \mathrm{C}$ and $170 \mathrm{rpm}$. The bacterial cells were collected by centrifugation (4000 g, $5 \mathrm{~min}$ ) and the pellet was re-suspended in sterile PBS. This washing process was repeated three times to remove nutrients, organic and inorganic impurities. The final concentration of bacterial cells in PBS solutions was adjusted to $10^{9} \mathrm{cfu} / \mathrm{ml}$ by use of spectrophotometer (Shimadzu UV-1601 PC, Japan) at $600 \mathrm{~nm}$. Each polymer sample was put in a well of a 6-well microtiter-plate and $7.5 \mathrm{ml}$ of bacterial cell suspension was added to each well and incubated for 60 minutes at $37^{\circ} \mathrm{C}$ and 90 rpm (Labnet shaker incubator) to assure proper adhesion to the surfaces. ${ }^{[20-23]}$ After the 
incubation period, the samples were gently rinsed with PBS and stained by ethidium bromide (0.05 \%, $45 \mathrm{~min})$. Fluorescent images were taken from the samples and analysed by ImageJ software (open source public domain software available to download from, http://imagej.nih.gov/ij/download.html) to determine the number of adhered bacteria on each sample.

\section{Results and Discussion}

The thickness, roughness and wettability of a deposited PPy film are important factors governing cell and bacterial adhesion, which is especially important to control when microfabricating sensors, actuators, scaffolds and medical devices based on PРy. Electropolymerisation is an easy and advantageous PPy deposition method. The polymerisation conditions as well as the type of counter ion affect the final physical properties of the film. ${ }^{[6,8 \text {, }}$ ${ }^{9]}$ In order to better understand the effect of each factor, different counter ions (small anion $(\mathrm{Cl})$, small negatively charge molecules (ToS, $\left.\mathrm{ClO}_{4}\right)$, the widely used counter ion (DBS) and a polyanionic polymer (PSS)) were used to fabricate polymer layers at two different constant potentials, and with and without catalyst. The results give us valuable information how to set the polymerisation conditions to yield PPy film with the desired properties suitable for the future research.

Table 1. Polymerisation conditions of PPy fabrication.

\begin{tabular}{|c|c|c|c|c|c|}
\hline $\begin{array}{c}\text { Polymerization } \\
\text { Conditions }\end{array}$ & I & II & III & IV & V \\
\hline Potential (mV) & 500 & 850 & 500 & 850 & 850 \\
\hline Charge (mC) & 200 & 200 & 200 & 200 & 800 \\
\hline $\begin{array}{c}\text { Catalyst } \\
\left(\mathrm{FeCl}_{3}\right)\end{array}$ & - & - & + & + & + \\
\hline
\end{tabular}

\subsection{Effect of potential}


The potential of the PPy electrodeposition has a critical effect on the final polymer film properties. To survey this effect, two different potentials, 0.500 and 0.850 , were chosen to fabricate PPy film with different counter ions. In our previous work we have synthesised a variety of PPy-surfaces using standard synthesis conditions, e.g. a synthesis potential of 0.650 $V \cdot{ }^{[24]}$ Here, we wanted to investigate the effect of more extreme synthesis conditions to create a wider span of dissimilar surfaces. We have taken a lower potential of $0.500 \mathrm{~V}$ and a higher potential of $0.850 \mathrm{~V}$ that still give good quality films. A potential lower than $0.500 \mathrm{~V}$ resulted in poor films and spot like coverage. A potential higher than $0.850 \mathrm{~V}$ resulted in overoxidised films. Figure 1a shows the effect of the low and high potential on the final film thickness. PPy film thickness is an important parameter needs to be considered and determined during electrodeposition because of its effects on the polymer properties, such as Young's modulus. Although electrochemical deposition of PPy is a stoichiometric process, many factors affect the film thickness including type of dopant, doping level, oligomers which remain in solution, side reactions, porosity and density of the final mass. The amount of consumed charge during electropolymerisation was kept equal and therefore the mass of the PPy in the final fabricated polymer layer is assumed to be equal. Hence, the impact of the different electrodeposition potentials as well as that of the dopant type on the final film thickness could be evaluated. At higher potentials a thicker film was formed except in the case of small counter ions $(\mathrm{Cl}$ and $\mathrm{ClO}_{4}$ ), where a higher potential had no effect on film thickness. The type of dopant had an effect on final film thickness too. It seems that there is a relationship between the size of dopant and the final film thickness, except in the case of $\mathrm{ClO}_{4}$ which resulted in much thicker films. Figure $1 \mathrm{~b}$ illustrates the relationship between the surface roughness and the polymerisation potential for the different dopants. Regardless of the type of dopant, higher potential led to higher surface roughness, with the exception of PSS (the typical thickness and roughness profiles of all films obtained using the profilometer and SEM images of all polymer samples are shown in the Supplementary Information). Figure 1c shows the contact angle, or wettability, 
of the various samples. Although is it clear that we can modify the contact angle by the synthesis conditions including the type of dopant, there does not seem to be a clear correlation between the dopant and the contact angle. Most dopants resulted in films with relatively high contact angles (65-80 degrees), while $\mathrm{ClO}_{4}$ gave a slightly lower contact angle. PSS was the exception and resulted in films with a very low contact angle of 15 degrees, probably due to the highly charged polyanion. In all cases, a higher synthesis potential resulted in a slightly increased contact angle, again, except for PSS where there is no statistically significant difference.
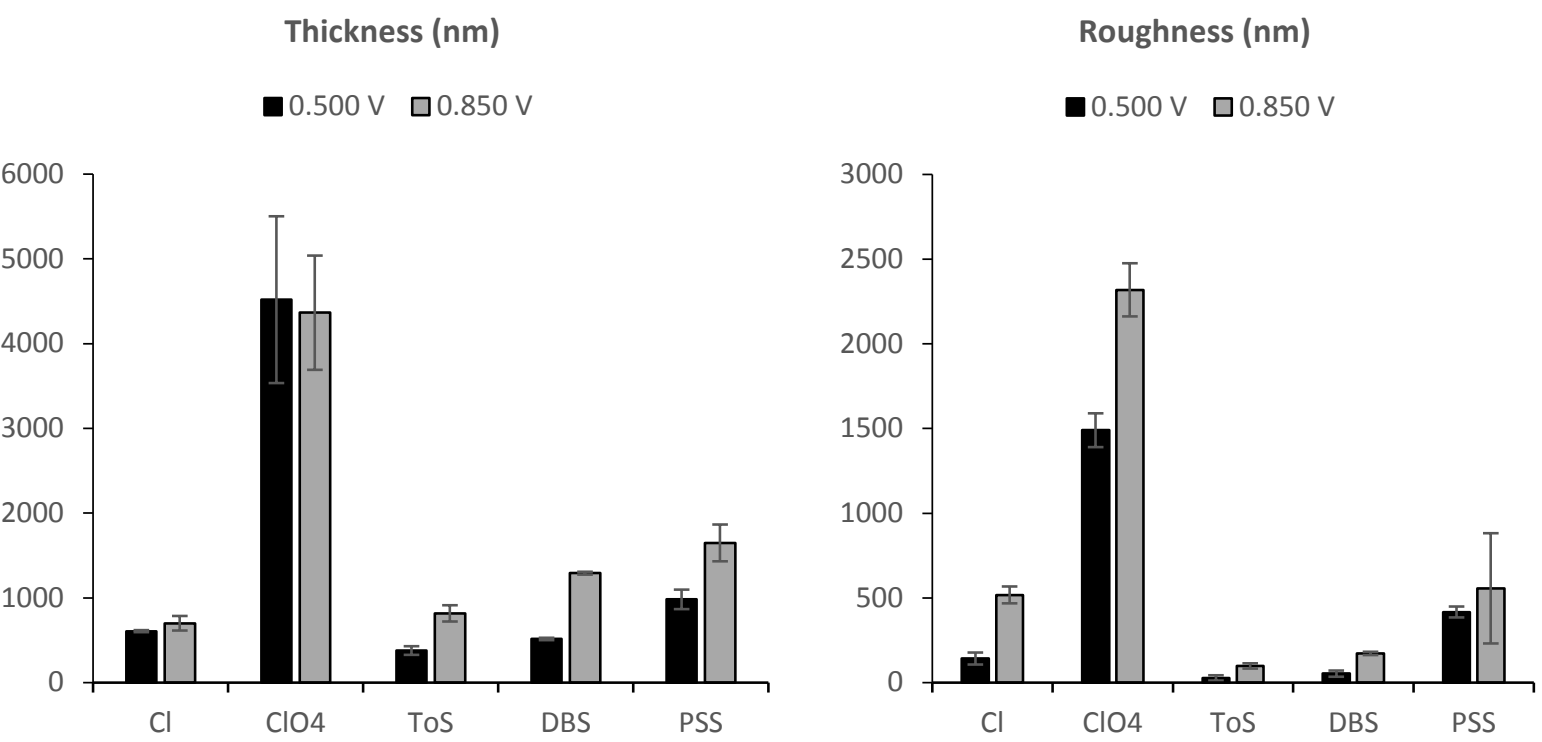

Water contact angle

口 $0.500 \mathrm{~V} \square 0.850 \mathrm{~V}$

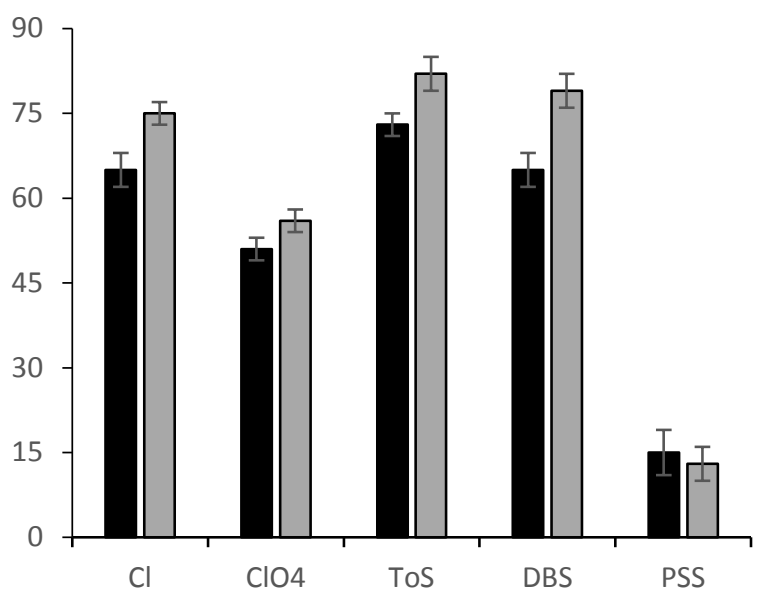

Figure 1. The effect of polymerisation potential on polypyrrole film thickness, roughness and wettability. Polymers were fabricated electrochemically using $0.1 \mathrm{M}$ pyrrole and 0.1 
M dopant in aqueous solution ( 0.500 vs 0.850 volt, charge $200 \mathrm{mC}$ ). The data are averages of three independent experiments and error bars indicate standard deviation.

\subsection{Effect of oxidant $\left(\mathrm{Fe}^{+3}\right)$}

The presence of low concentration of $\mathrm{Fe}^{3+}$ ions $(<1 \mathrm{mM})$ during the electrochemical polymerisation of PPy can play a role similar to a catalyst. $\mathrm{Fe}^{3+}$ promoted a chemical polymerisation of pyrrole monomers in parallel to the electrochemical effect and was reduced to $\mathrm{Fe}^{2+}$. This combination of chemical and electrochemical synthesis caused the polymer to grow faster, with a consequently porous structure and a rougher surface. ${ }^{[15]}$ Figure 2a shows the result of adding $\mathrm{Fe}^{3+}$ ions to the polymerisation solution at $0.500 \mathrm{~V}$ and Figure 3a at $0.850 \mathrm{~V}$, respectively. Adding $\mathrm{Fe}^{3+}$ generally led to thicker PPy films, except for $\mathrm{ClO}_{4}$ at $0.500 \mathrm{~V}$, where the thickness was constant, and PSS at $0.850 \mathrm{~V}$, where the thickness was reduced. Comparing the surface roughness in Figure 2b and $3 b$ and the surface morphology of the films (SEM images in supplementary information) clearly shows the impact of the presence of $\mathrm{Fe} 3+$ on the fabricated film properties. For all dopants, adding $\mathrm{Fe}^{3+}$ resulted in an increase in surface roughness, except for PSS where the roughness decreased (although this was not statistically significant at $0.850 \mathrm{~V}$ due to one large error bar). Polymer roughness is very important for mechanical and biological applications. For example, there is a direct correlation between cellular adhesion strength and surface roughness in materials such as polymers with lower surface energy. ${ }^{[25]}$ So, tuning the polymer surface morphology with the desired roughness could help to optimise its surface properties for use in a variety of applications. It has already been reported that differently doped PPy films grown under the same synthesis conditions have different roughness; here we show that adding a catalyst also has an effect on the surface roughness and morphology. Figures $2 \mathrm{c}$ and 3c show the effect of $\mathrm{Fe}^{3+}$ addition on the contact angle. Similar to the effect of synthesis potential, we can modify the contact angle by the 
synthesis conditions, but again the dopant is an important variable with a variety of effects. At $0.500 \mathrm{~V}$ we observed increased contact angle (Tos and DBS), reduced contact angle (Cl and PSS) and no significant effect, while at $0.850 \mathrm{~V}$ the changes were not significant $\left(\mathrm{ClO}_{4}, \mathrm{ToS}\right.$, PSS), reduced contact angle (Cl) or increased contact angle (DBS).
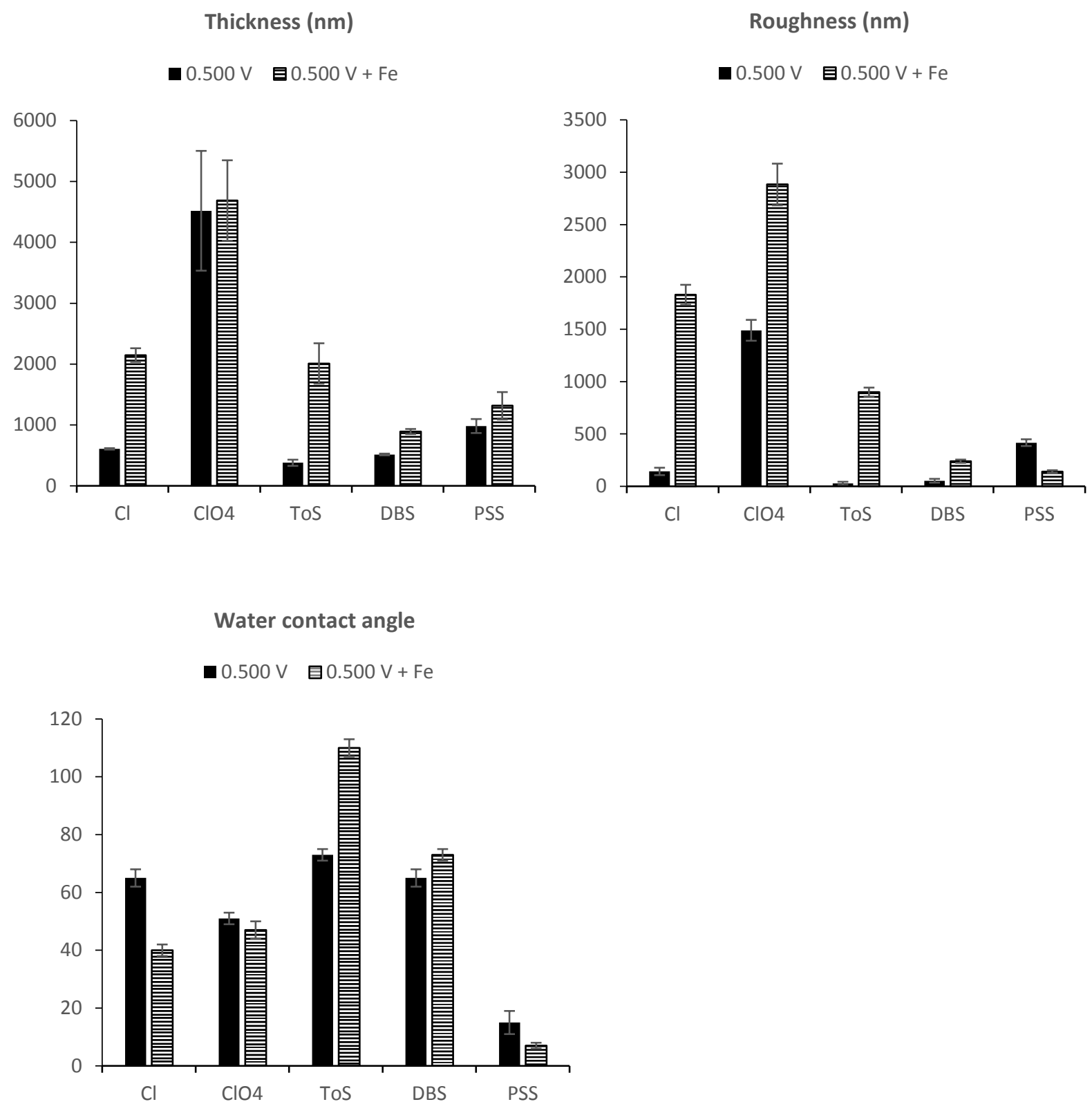

Figure 2. The effect of Fe on polypyrrole film thickness, roughness and wettability.

Polymers were fabricated electrochemically using $0.1 \mathrm{M}$ pyrrole and $0.1 \mathrm{M}$ dopant in 
aqueous solution (with and without $1 \mathrm{mM} \mathrm{FeCl3}$, charge $200 \mathrm{mC}$ ). The data are averages of three independent experiments and error bars indicate standard deviation.

\subsection{Effect of consumed charge}

To expand the survey of the effect of polymerisation conditions on the physical-chemical properties of PPy, the role of the consumed charge during synthesis (Q) was also investigated. Above we have shown that the surface properties can be tuned by altering the synthesis potential or adding $\mathrm{Fe}^{3+}$, but these properties might change by continuing the polymerisation. For example, it has been reported that the roughness of PPy -ToS and -Cl increase with thickness, but PPy-PSS remains constant. ${ }^{[7]}$ Comparing the results shown in Figure 3a, reveals that the thicknesses of the films synthesised using a larger Q was higher for all samples, as would be expected because of the linear relationship between the charges passed during electropolymerisation and the final polymer mass. Roughness also increased with longer synthesis, shown in Figure 3b, although polymer doped with $\mathrm{ClO}_{4}$ showed a different behaviour, a reduction in roughness.

In Figure 3c, the wettability of different doped polypyrroles under different synthesis conditions is shown. This figure shows the impact of the dopant type on the final PPy film wettability. More charge, i.e. a longer polymerisation time, did not affect the contact angle for $\mathrm{Cl}$, ToS and DBS doped polymers, but resulted in a significant reduction of the contact angle with both $\mathrm{ClO}_{4}$ and PSS. Although the type of dopant had a large influence on the PPy film wettability, here it is demonstrated that there is a potential to tune this property of the PPy film by changing the polymer structure during electropolymerisation by altering the synthesis conditions. 
Thickness (nm)
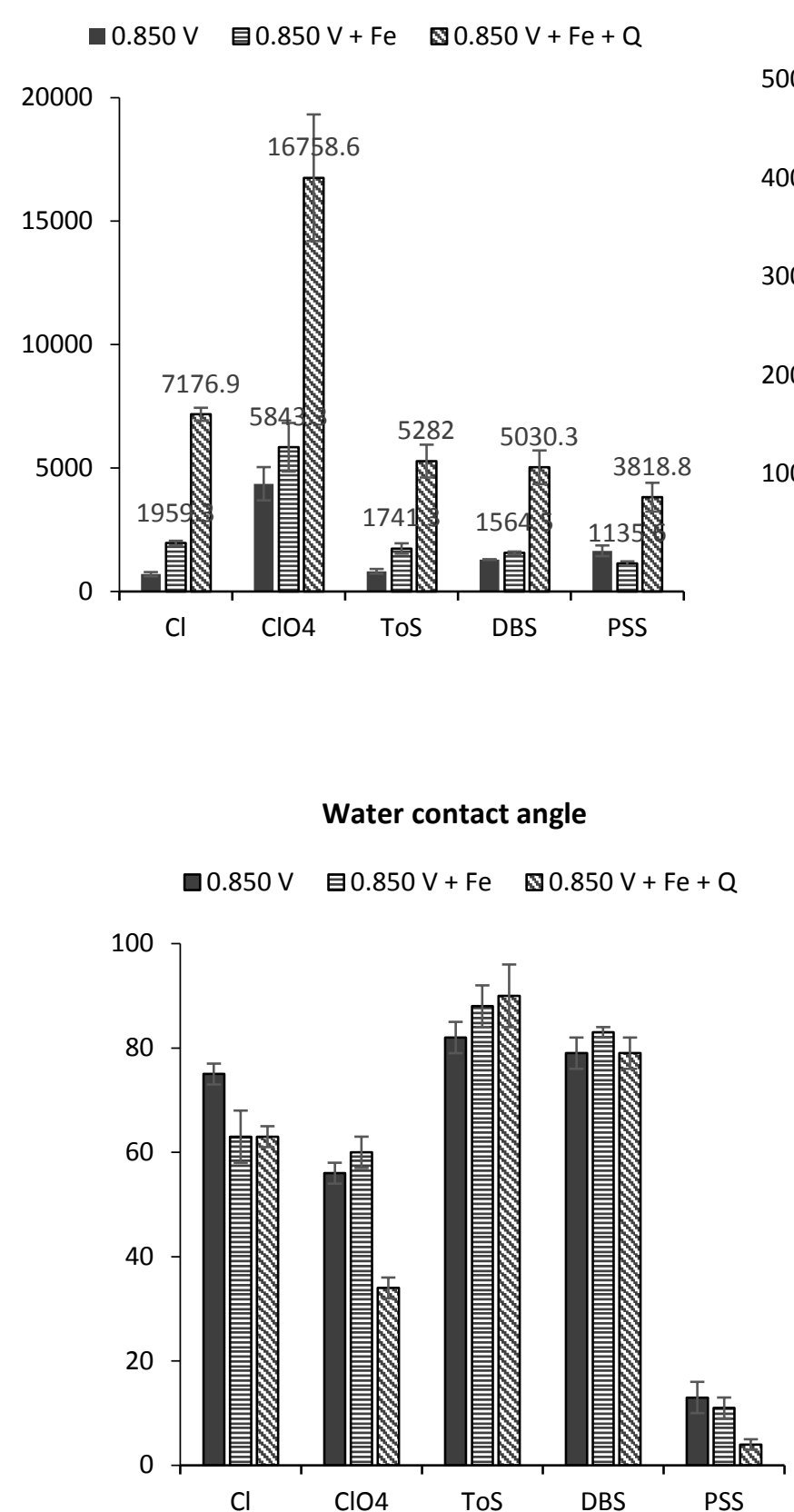

Figure 3. The effect of Fe and Q on polypyrrole film thickness, roughness and wettability. Polymers were fabricated electrochemically using $0.1 \mathrm{M}$ pyrrole and $0.1 \mathrm{M}$ dopant in aqueous solution (with and without $1 \mathrm{mM} \mathrm{FeCl}_{3}$, charge 200 vs $800 \mathrm{mC}$ ). The data are averages of three independent experiments and error bars indicate standard deviation. 
The data in Figures 2 and 3 may serve as a guide as to how to set polymerisation conditions to yield specific surface properties, such as roughness, in the final PPy film. It demonstrates the possibility of tuning PPy film roughness, thickness and wettability by setting appropriate polymerisation conditions. The typical thickness and roughness profiles of all films reported in this work obtained using the profilometer and also SEM images are shown in the Supplementary Information. Comparing SEM images reveals that not only polymer roughness was affected by adjusting the polymerisation conditions (including the consumed charge Q), but also the film morphology could be tuned. For example, in the case of PPy-ToS, adding $1 \mathrm{mM} \mathrm{Fe} 3+$ ions to the electropolymerisation solution resulted in sporadic micro-sized cauliflower shapes on the PPy surface, as compared to PPy-ToS without Fe3+, which had a smooth surface. Adjusting the synthesis parameters as proposed here, might provide an easier approach to altering PPy roughness and morphology than previously reported methods such as applying ultrasound during polymerisation. ${ }^{[26]}$

\subsection{Bacterial adhesion on the polymers}

Polymer chemical composition, charge, roughness and wettability potentially affect cell and bacterial adhesion. ${ }^{[27]}$ By controlling the surface physical-chemical properties, bacterial and cell adhesion can be controlled. Controlling bacterial adhesion to the PPy surface has been achieved by different strategies like coating the surface with specific types of protein ${ }^{[28]}$ or applying a direct or pulsed electric current or potential through the film. ${ }^{[29,30]}$ We have previously shown that the adhesion also depends on the dopant and redox state of PPy. ${ }^{[24]}$ In order to investigate the effect of the surface physical-chemical properties of PPy on bacterial adhesion, we have chosen a set of 4 PPy surfaces from the previous 25 different variants that either have similar roughness with different contact angles, or similar contact angles with different roughness. That is DBS II $(0.850 \mathrm{~V})$, DBS V $(0.850 \mathrm{~V}+\mathrm{Fe}+\mathrm{Q})$, PSS III $(0.500 \mathrm{~V}+\mathrm{Fe})$ and PSS V $(0.850 \mathrm{~V}+$ Fe+ Q). DBS II and DBS V as well as PSS III and PSS V have the same contact angle, while PSS III and DBS II as well as PSS V and DBS V have the same roughness. Figure 4a shows an 
SEM image, profilometer curve, wettability image and fluorescent image of adhered bacteria for each of the 4 polymer surfaces, and Figure 4b quantifies the amount of bacteria adhered to each surface. PPy-DBS seemed to present a more attractive surface for E.coli adhesion compared to PPy-PSS, which might be related to the higher hydrophobicity of these films. There are many papers on the effect of wettability on bacterial adhesion, but they often conclude differently, since bacterial adhesion is a complex phenomenon that is difficult to explain based on one parameter. The E.coli strain used in this study, showed a greater adhesion tendency to PPy-DBS V (0.850 V, Fe, Q) and less to PPy-PSS III (0.500 V, Fe), which is in accordance with the results of Myint et al. ${ }^{[23]}$ who showed that initial bacteria adhesion is considerably higher on hydrophobic and rough surfaces compared to hydrophilic and smooth material. It seems that superhydrophobic and superhydrophilic surfaces have a negative effect on bacterial adhesion and that the most favourable surfaces in terms of wettability are in the middle range. ${ }^{[31]}$ Figure 4 also reveals that the rougher surfaces were more favourable for adhesion, which is related to the fact that rougher surfaces present more surface area for the bacteria to interact with. In addition to a rougher surface, it has also been observed that the topography of a film affects bacterial adhesion, for example grooves and scratches in the size range of bacteria increase binding potential between bacterial cells and the surface and therefore facilitates bacterial attachment and colonisation. ${ }^{[32]}$ Moreover, in studying the role of polymer chemistry and topography in bacterial adhesion, Epaillard et al. ${ }^{[33]}$ highlighted the impact of peak and valley distribution on the same scale as bacterial dimensions on the polymer surface; mechanical adhesion and cell entrapment in the hollow structures, adds a further parameter to be taken into consideration for effective polymer film design. 


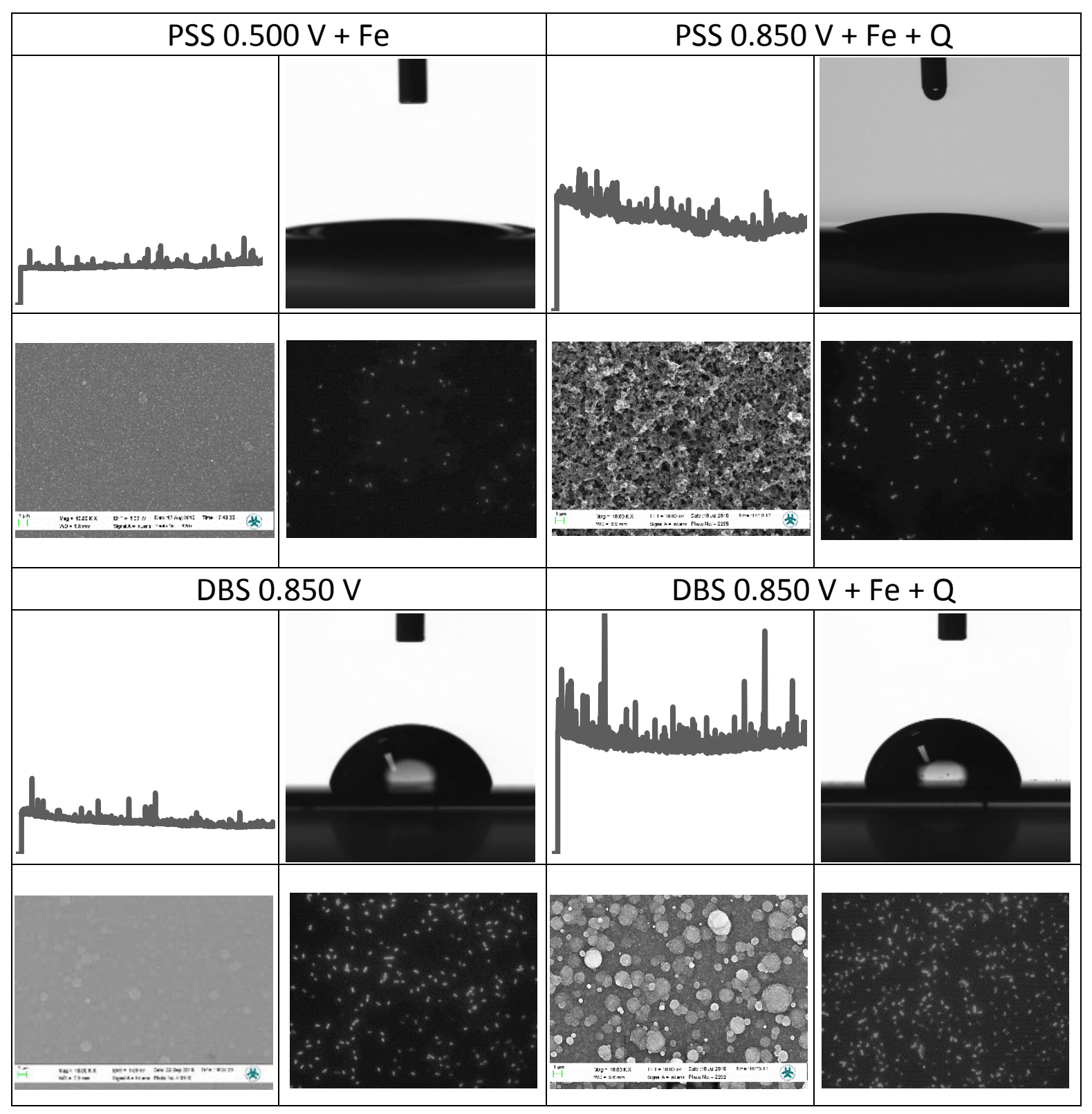

a) 


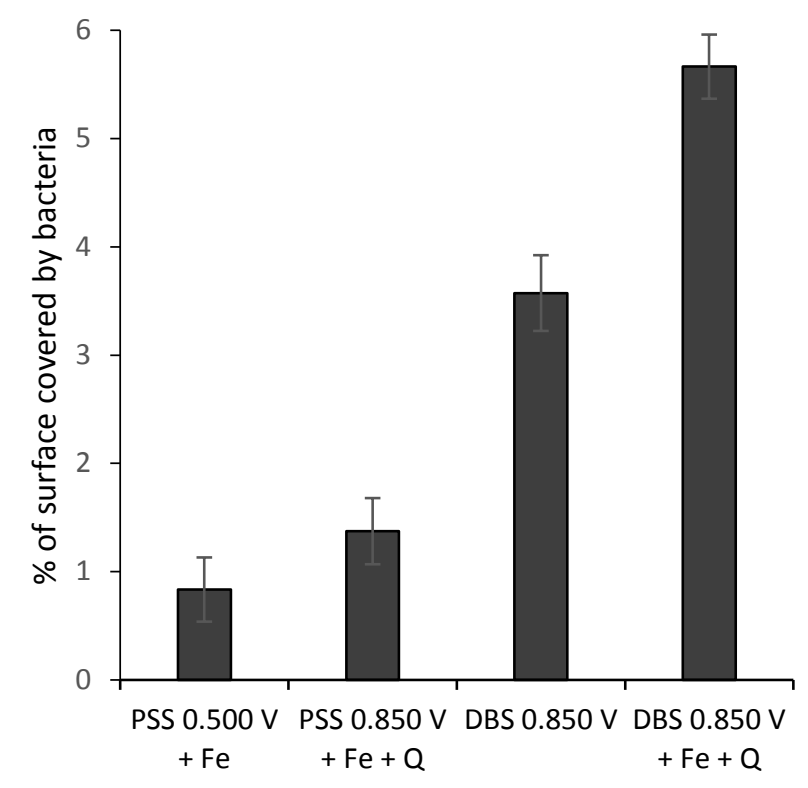

b)

Figure $4 a$. Surface profilometer, wettability, SEM and fluorescent image of four different PPy films synthesised in different conditions, DBS II $(0.850 \mathrm{~V})$, DBS V $(0.850 \mathrm{~V}+\mathrm{Fe}+$ Q), PSS III $(0.500 \mathrm{~V}+\mathrm{Fe})$ and PSS V $(0.850 \mathrm{~V}+\mathrm{Fe}+\mathrm{Q})$, that have similar roughness with different contact angles, or similar contact angles with different roughness. That is DBS II and DBS V as well as PSS III and PSS V have the same contact angle, while PSS III and DBS II as well as PSS V and DBS V have the same roughness (the colorful version of the figure is shown in the Supplementary Information) b. The percentage of the surface covered by bacteria for the four different PPy surfaces of (a). Comparing $1 \& 2$ and $3 \& 4$, shows that roughness increased the number of bacteria. Comparing $1 \& 3$ and $2 \& 4$ shows that higher contact angles increased bacterial adhesion; the bacteria used prefer a less hydrophilic surface. $\left(\sim 80^{\circ}\right)$.

\section{Conclusions}

Here we demonstrate the possibility of tuning the surface properties of PPy to control bacterial adhesion. The effect of using different dopants, polymerisation conditions and the presence or 
absence of $\mathrm{Fe}^{3+}$ ions on the properties of the polymer, including roughness, thickness and wettability, was explored. The main conclusions are: (1) the wettability of the PPy depends to a large extent on the type dopant used. PSS, which is an anionic polymer, endows the PPy with hydrophilic properties, whereas the other dopants $\left(\mathrm{Cl}, \mathrm{ClO}_{4}\right.$, ToS and DBS) created a more hydrophobic surface, with ClO4 having a slightly lower contact angle (CA $~ 50^{\circ}$ vs CA 65$80^{\circ}$ ). Although the wettability of PPy is mostly dictated by the type of dopant, it could be tuned throughout fabrication by altering the polymerisation potential or adding $\mathrm{Fe}^{3+}$ ions. (2) The roughness of the final PPy layer could be tuned by choosing the appropriate counter ion, synthesis potential, consumed charge and adding $\mathrm{Fe}^{3+}$. The surface morphology of the PPy could also be manipulated by the choice of the fabrication method. (3) The surface properties of the resulting PPy films affected bacterial adhesion. Changing the surface roughness and wettability was shown to be a good way to control the initial adhesion of bacteria. PPy-DBS, which has a more hydrophobic surface, accommodated more bacteria in comparison with PPyPSS, with a hydrophilic surface. Likewise, PPy-DBS and PPy-PSS with a rough surface, attracted more bacteria as compared to smooth PPy-DBS and PPy-PSS surfaces. By taking advantage of controlling initial bacterial adhesion we can regulate biofilm formation by tuning the surface properties. Here we show that we can statically control the initial adhesion by altering the synthesis conditions. This provides an extension to our previous work, where we proved the feasibility of using a set of polymers with different properties in an array for bacterial differentiation; the surface properties of the polymers were tuned both statically by choice of the dopant, and dynamically, by altering the redox state of the PPy.

\section{Supporting Information}

Supporting Information is available from the Wiley Online Library or from the author. 
Acknowledgments: Mohsen Golabi acknowledges the Iranian Ministry of Science, Research and Technology for supporting his Ph.D. Anthony P F Turner and Edwin W.H. Jager thank Linköping University and the Swedish Research Council (VR-2014-3079) for financial support.

Keywords: polypyrrole roughness, polymer thickness, wettability, modulating bacterial adhesion, biopolymer surface

[1] P. M. George, A. W. Lyckman, D. A. Lavan, A. Hegde, Y. Leung, R. Avasare, C. Testa, P. M. Alexander, R. Langer, M. Sur, Biomaterials 2005, 26, 3511.

[2] S. Tokonami, Y. Nakadoi, M. Takahashi, M. Ikemizu, T. Kadoma, K. Saimatsu, L. Q. Dung, H. Shiigi, T. Nagaoka, anal. chem 2013, 85, 4925.

[3] N. K. Guimard, N. Gomez, C. E. Schmidt, Progress in Polymer Science 2007, 32, 876.

[4] A. Herland, K. M. Persson, V. Lundin, M. Fahlman, M. Berggren, E. W. H. Jager, A. I. Teixeira, Angewandte Chemie-International Edition 2011, 50, 12529.

[5] D. Q. Le, M. Takai, S. Suekuni, S. Tokonami, T. Nishino, H. Shiigi, T. Nagaoka, anal. chem 2015, 87, 4047.

[6] S. Sadki, P. Schottland, N. Brodie, G. Sabouraud, Chemical Society Reviews 2000, 29, 283. [7] J. M. Fonner, L. Forciniti, H. Nguyen, J. D. Byrne, Y. F. Kou, J. Syeda-Nawaz, C. E. Schmidt, Biomedical Materials 2008, 3.

[8] S. Carquigny, O. Segut, B. Lakard, F. Lallemand, P. Fievet, Synthetic Metals 2008, 158, 453.

[9] A. Kaynak, Materials Research Bulletin 1997, 32, 271.

[10] C. Desrousseaux, V. Sautou, S. Descamps, O. Traore, Journal of Hospital Infection 2013, 85, 87.

[11] M. Katsikogianni, Y. F. Missirlis, European Cells and Materials 2004, 8, 37.

[12] S. H. Yoon, J. Chang, L. Lin, M. R. K. Mofrad, Lab on a Chip - Miniaturisation for Chemistry and Biology 2011, 11, 3555.

[13] M. Lorenzetti, I. Dogša, T. Stošicki, D. Stopar, M. Kalin, S. Kobe, S. Novak, ACS Applied Materials and Interfaces 2015, 7, 1644.

[14] D. Alves, M. Olívia Pereira, Biofouling 2014, 30, 483.

[15] L. B. Xu, W. Chen, A. Mulchandani, Y. S. Yan, Angewandte Chemie-International Edition 2005, 44, 6009.

[16] T. V. Vernitskaya, O. N. Efimov, Uspekhi Khimii 1997, 66, 502.

[17] T. W. Lewis, G. G. Wallace, C. Y. Kim, D. Y. Kim, Synthetic Metals 1997, 84, 403.

[18] T. F. Otero, M. Márquez, I. J. Suárez, Journal of Physical Chemistry B 2004, 108, 15429.

[19] M. Zhou, J. Heinze, Electrochimica Acta 1999, 44, 1733.

[20] P. E. Vaudaux, P. Francois, R. A. Proctor, D. McDevitt, T. J. Foster, R. M. Albrecht, D. P. Lew, H. Wabers, S. L. Cooper, Infect. Immun. 1995, 63, 585.

[21] J. Li, H. J. Busscher, H. C. van der Mei, J. Sjollema, Biofouling 2013, 29, 11.

[22] R. P. George, P. Muraleedharan, K. R. Sreekumari, H. S. Khatak, Biofouling 2003, 19, 1.

[23] A. A. Myint, W. Lee, S. Mun, C. H. Ahn, S. Lee, J. Yoon, Biofouling 2010, 26, 313.

[24] M. Golabi, A. P. F. Turner, E. W. H. Jager, Sensors and Actuators B: Chemical 2016, 222, 839.

[25] N. J. Hallab, K. J. Bundy, K. O'Connor, R. L. Moses, J. J. Jacobs, Tissue Engineering 2001, 7, 55 . 
[26] J. Dejeu, A. E. Taouil, P. Rougeot, S. Lakard, F. Lallemand, B. Lakard, Synthetic Metals 2010, 160, 2540.

[27] B. Lakard, L. Ploux, K. Anselme, F. Lallemand, S. Lakard, M. Nardin, J. Y. Hihn, Bioelectrochemistry 2009, 75, 148.

[28] C. Tedjo, K. G. Neoh, E. T. Kang, N. Fang, V. Chan, Journal of Biomedical Materials Research - Part A 2007, 82, 479.

[29] J. Zhang, K. G. Neoh, X. Hu, E.-T. Kang, Biomaterials 2014, 35, 7690.

[30] G. Schaule, A. Rumpf, C. Weidlich, K. M. Mangold, H. C. Flemming, "Effects of electric polarization of indium tin oxide (ITO) and polypyrrole on biofilm formation", in Water Sci. Technol., 2008, p. 58/2165.

[31] X. X. Zhang, L. Wang, E. Levanen, Rsc Advances 2013, 3, 12003.

[32] C. Sousa, D. Rodrigues, R. Oliveira, W. Song, J. F. Mano, J. Azeredo, AMB Express 2011, $1,1$.

[33] F. Poncin-Epaillard, J. M. Herry, P. Marmey, G. Legeay, D. Debarnot, M. N. BellonFontaine, Materials Science and Engineering: C 2013, 33, 1152. 


\section{Supporting Information}

Tuning the surface properties of polypyrrole films for modulating bacterial adhesion

Mohsen Golabi, Anthony P F Turner, Edwin W H Jager*

S1. SEM image and profilometer of PPy doped films synthesised under different conditions.

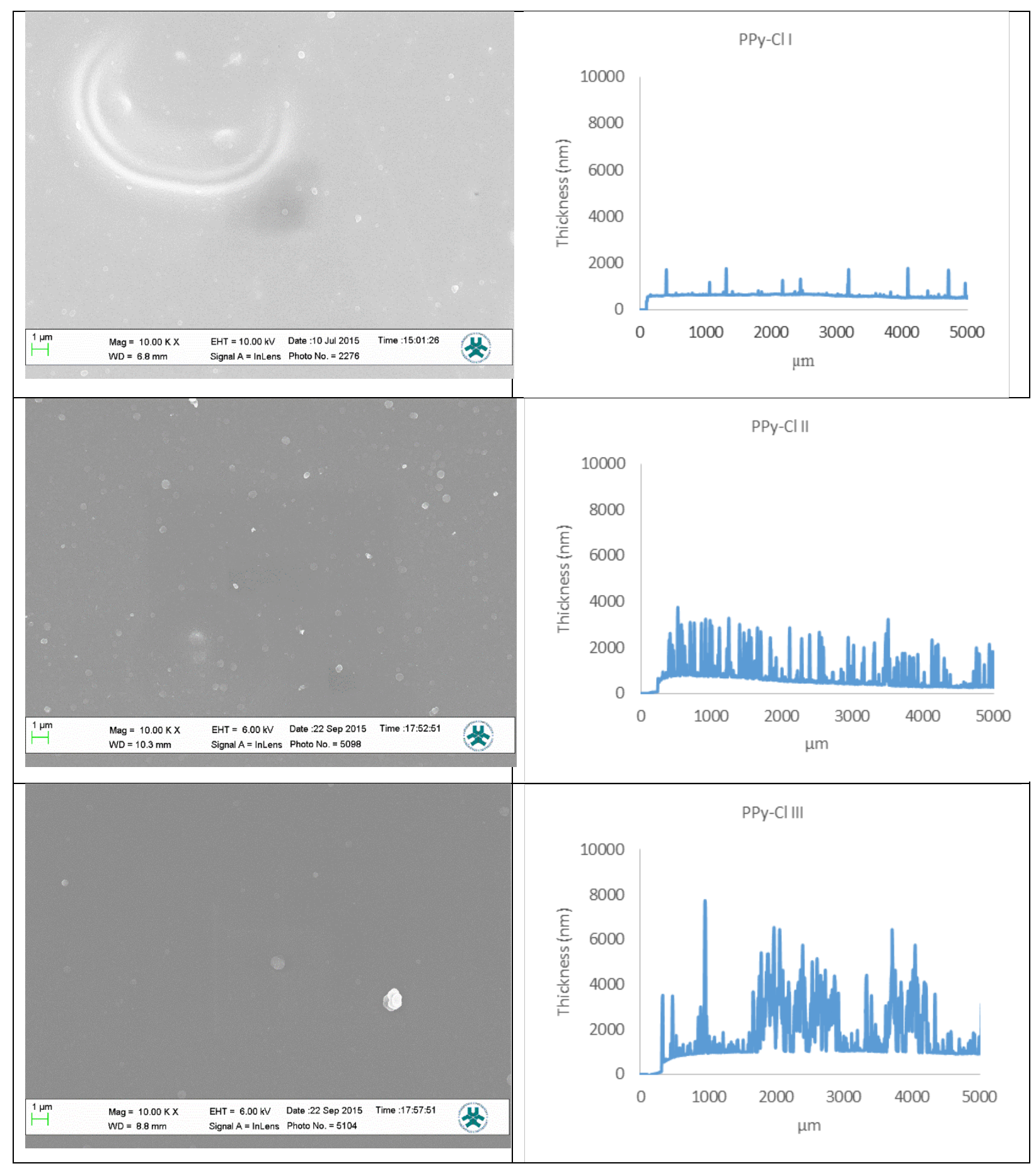




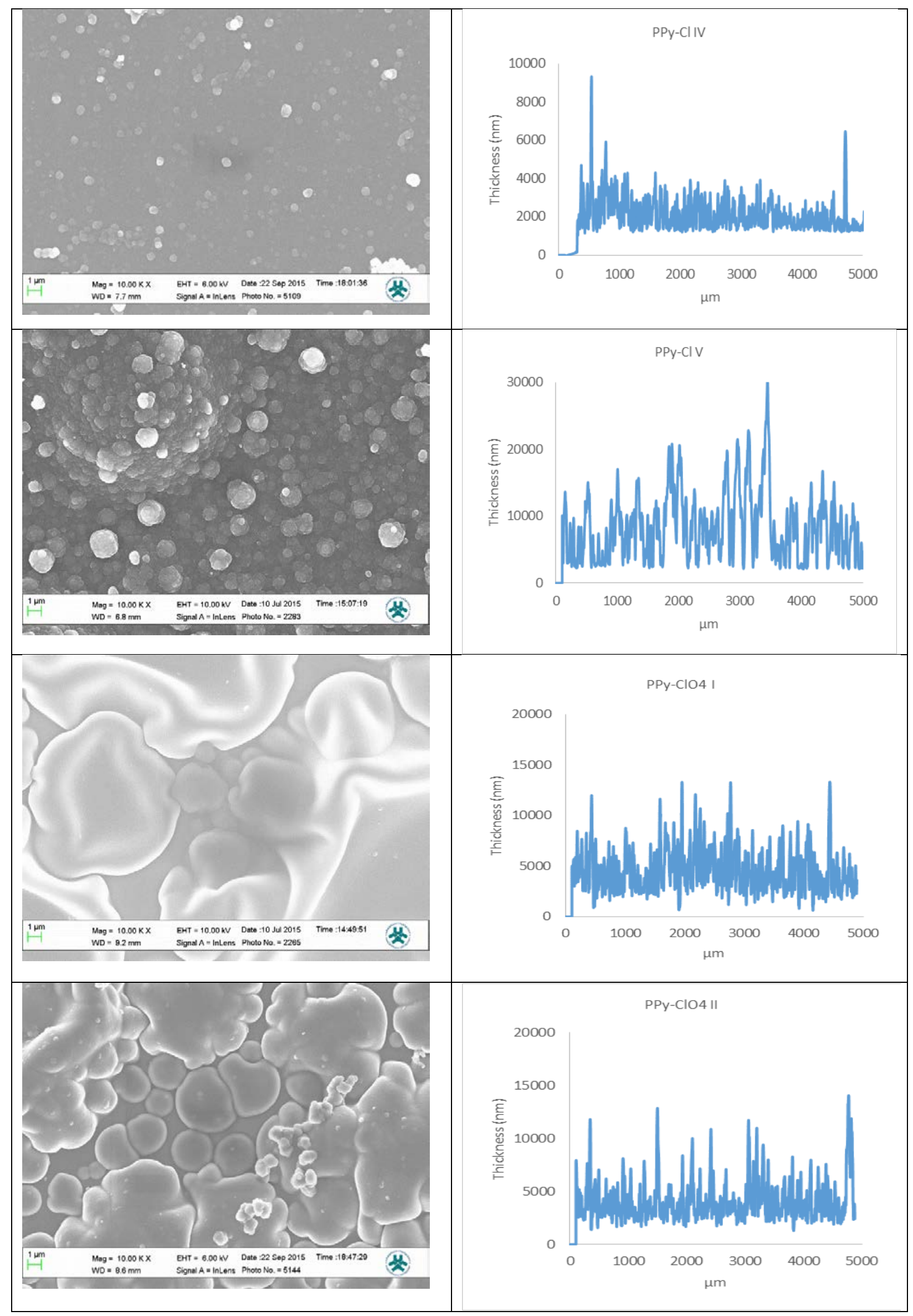




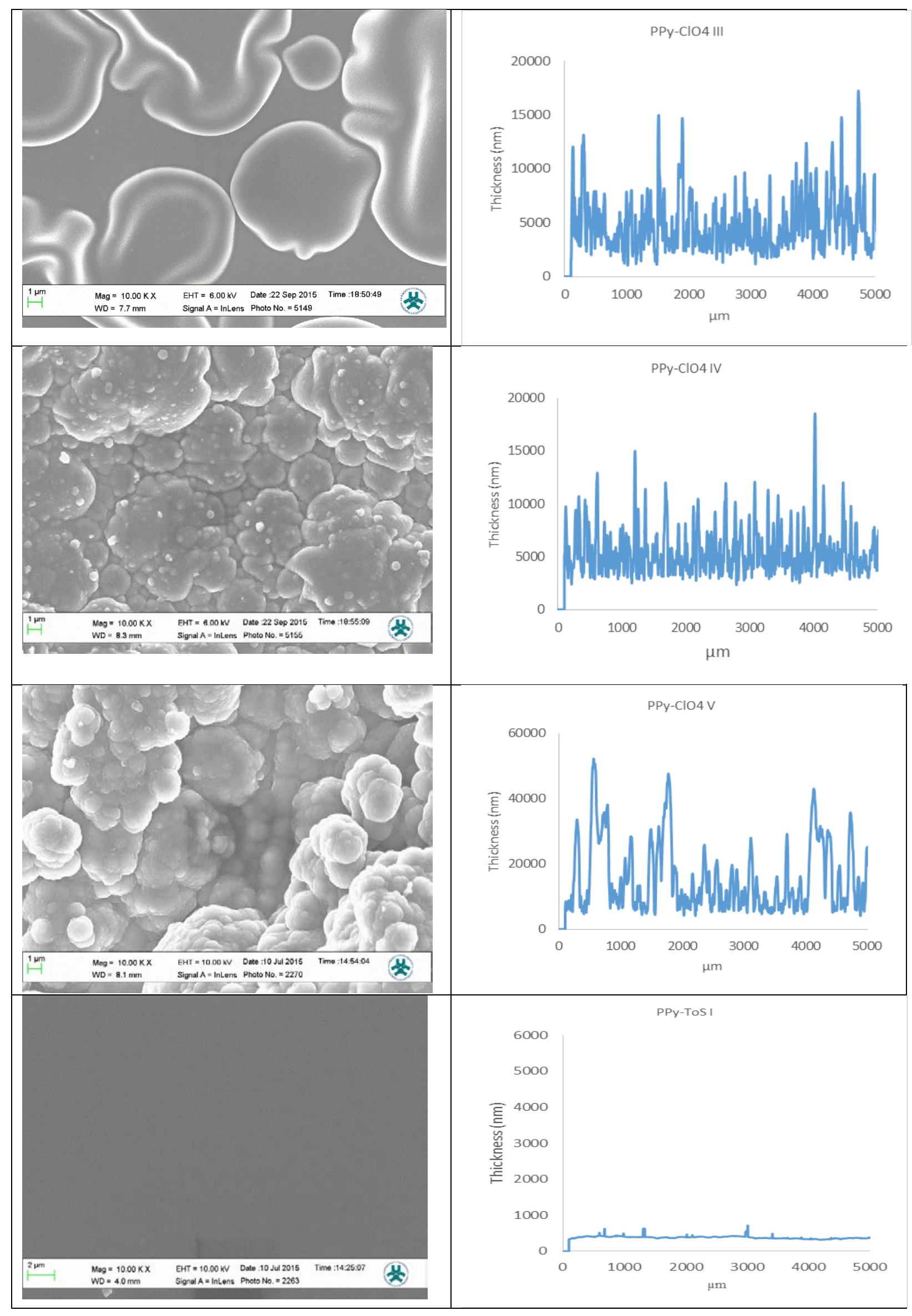




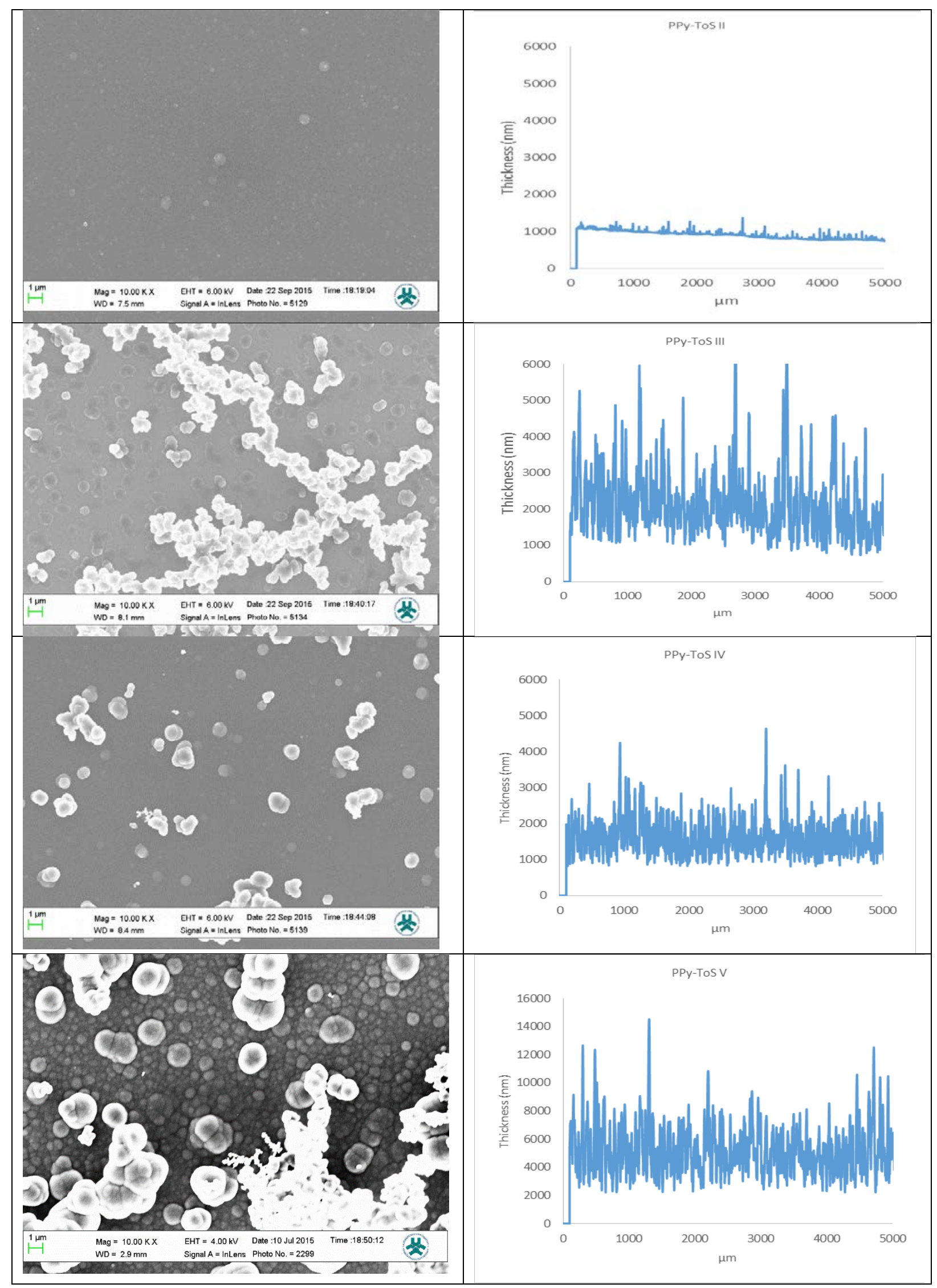




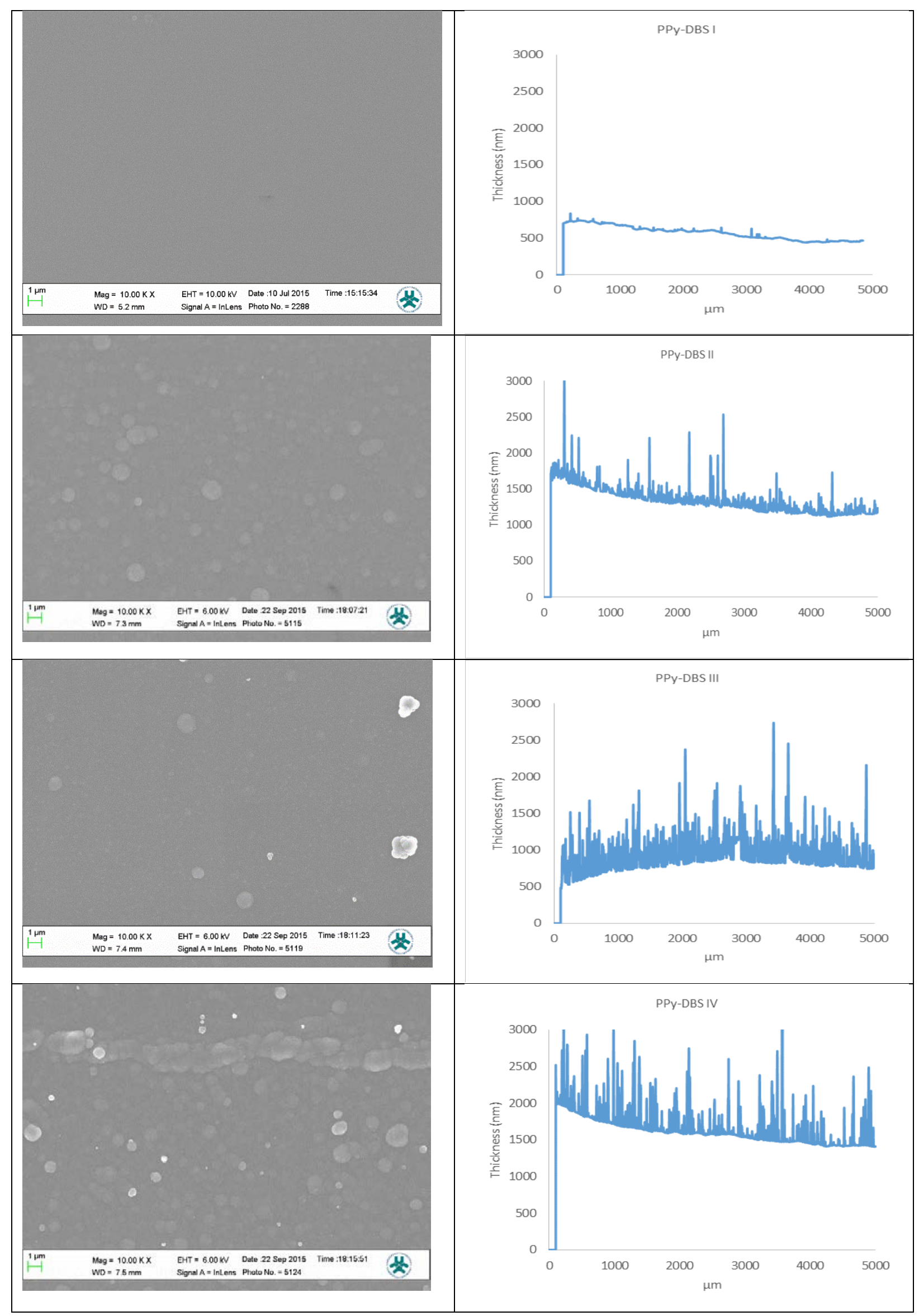




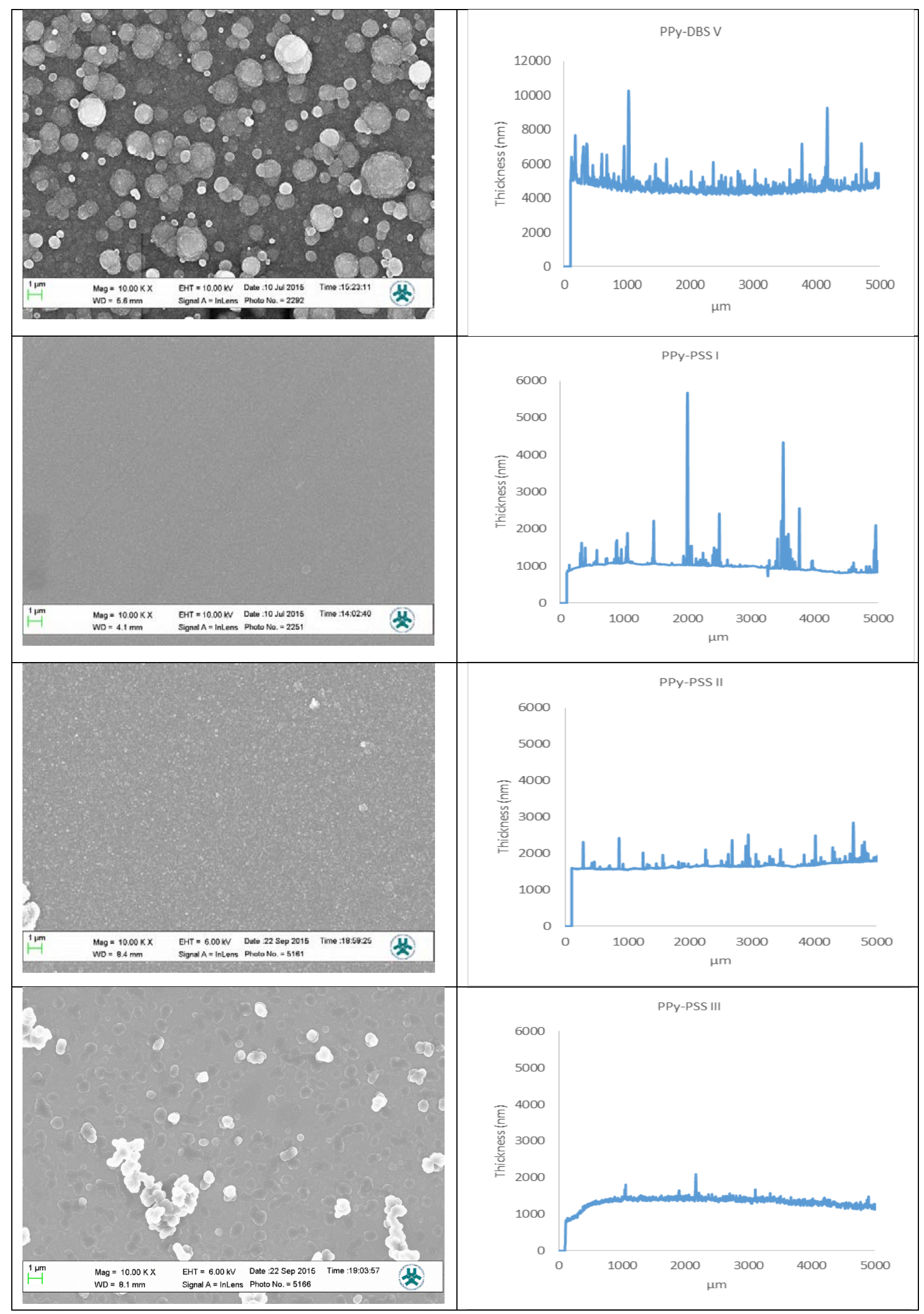




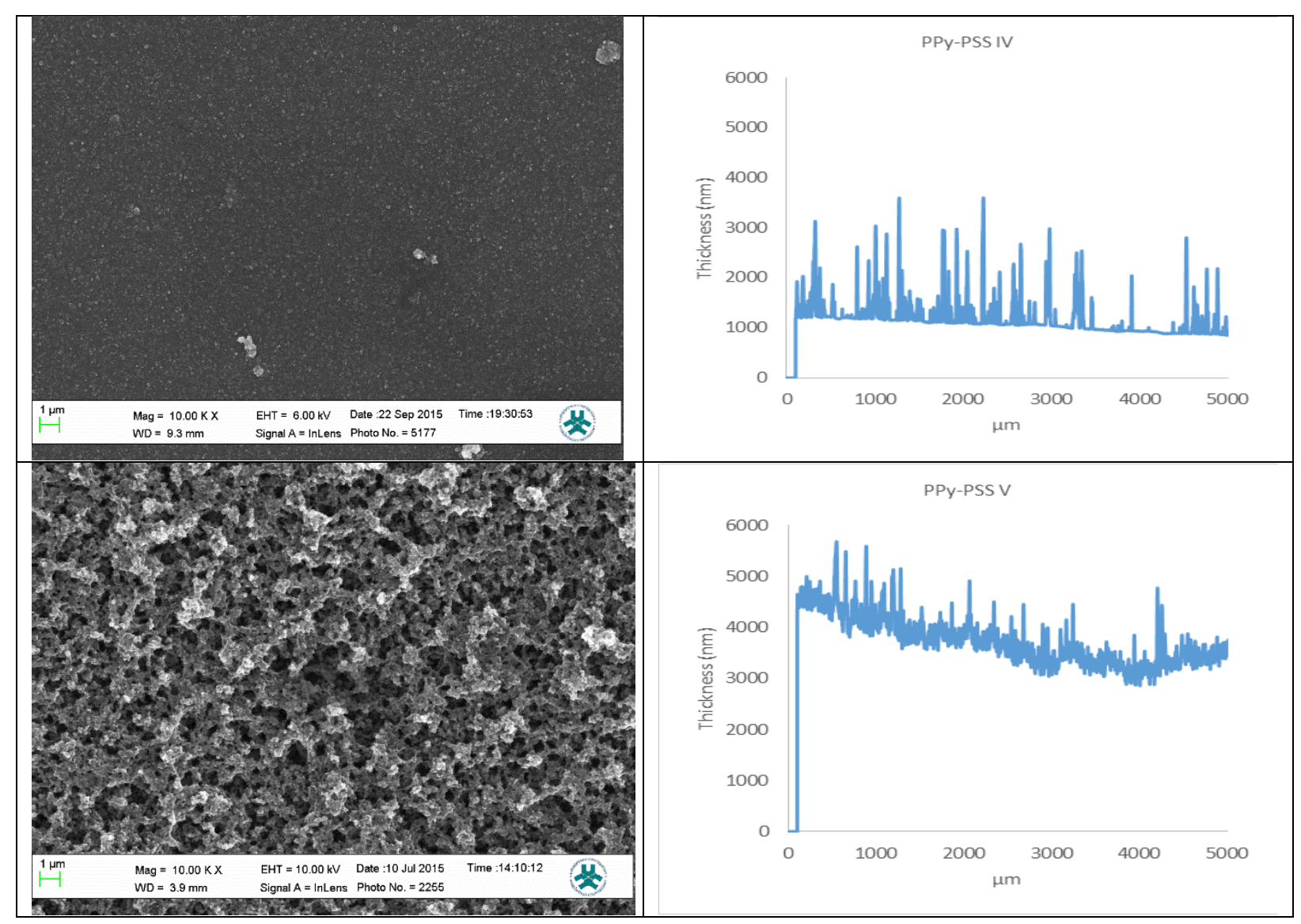


S2. Colorful version of figure $4 \mathrm{a}$.

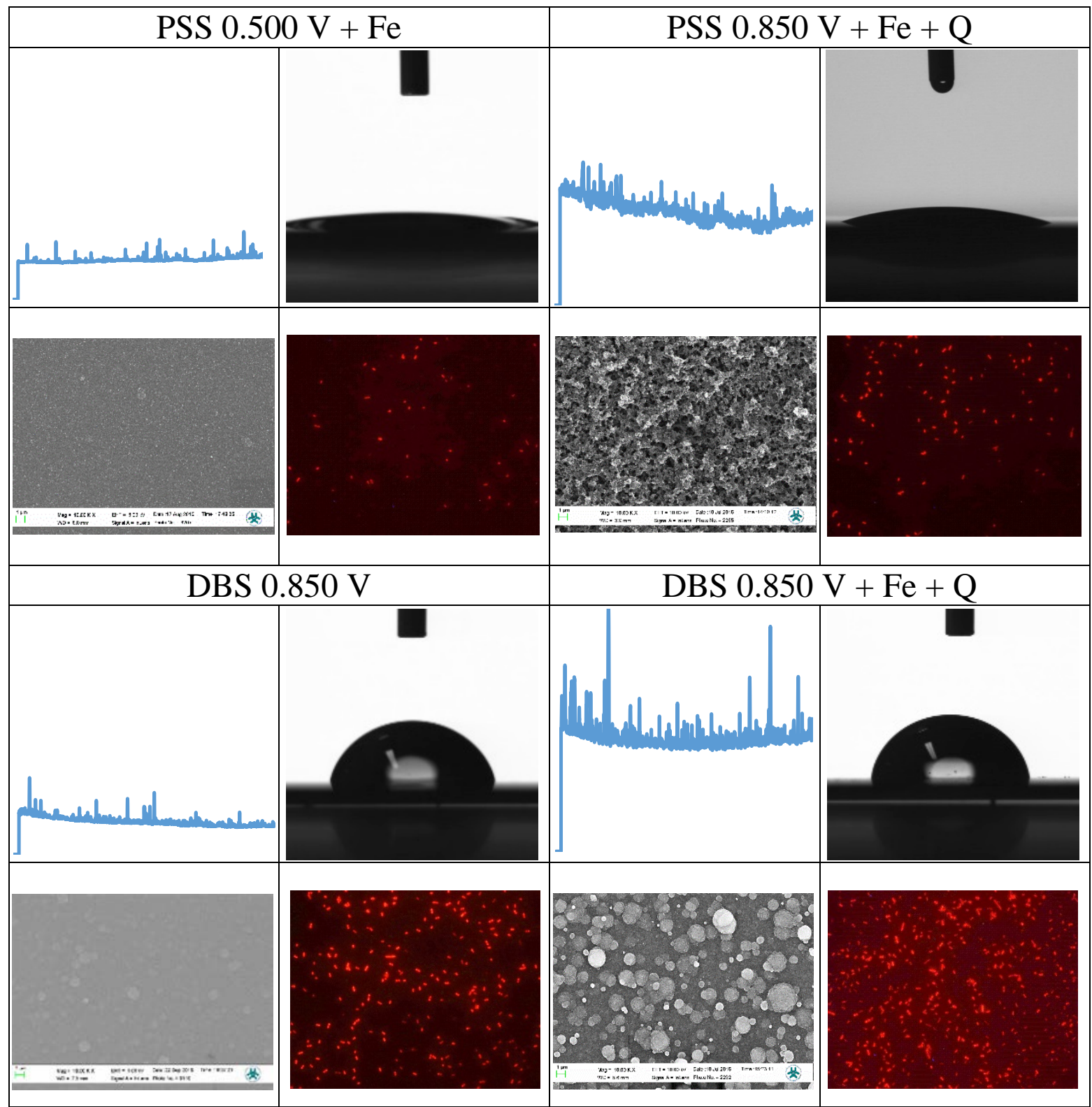

